\title{
FORMAÇÃO DO ESTADO BRASILEIRO: ENTRE O PATRIMONIALISMO E O DESENVOLVIMENTISMO
}

\author{
FORMACIÓN DEL ESTADO BRASILEÑO: ENTRE EL PATRIMONIALISMO Y EL \\ DESARROLISMO
}

\author{
FORMATION OF THE BRAZILIAN STATE: BETWEEN PATRIMONIALISM AND \\ DEVELOPMENTALISM
}

\author{
Matheus Silveira LIMA ${ }^{1}$
}

RESUMO: Este trabalho apresenta um debate importante que conecta reflexões da sociologia com a teoria econômica a partir de um mesmo tema: o papel do Estado no Brasil e a importância da herança de Portugal. Analisaremos sociologicamente a conexão entre a construção política patrimonialista e o surgimento do capitalismo comercial, que resulta em um bloqueio da democracia e da modernização do Estado, e de uma perspectiva econômica, a abordagem do mesmo tema do Estado como propulsor do desenvolvimento ao longo do século XX, até a década de 1980, quando perdem forças as estratégias de crescimento e modernização pelo viés desenvolvimentista, passando a orientarem-se cada vez mais por uma econômica de mercado.

PAlaVRAS-CHAVE: Patrimonialismo. Formação do Estado. Capitalismo. Desenvolvimentismo.

RESUMEN: Este artículo presenta un debate importante que conecta las reflexiones de la sociología con la teoría económica basada en el mismo tema: el papel del estado en Brasil y la importancia de la herencia de Portugal. Analizaremos sociológicamente la conexión entre la construcción política patrimonialista y el surgimiento del capitalismo comercial, que resulta en un bloqueo de la democracia y la modernización del estado, y desde una perspectiva económica, el enfoque del mismo tema del estado como motor del desarrollo a lo largo del siglo. XX, hasta la década de 1980, cuando las estrategias de crecimiento y modernización a partir del sesgo del desarrollo pierden fuerza y se orientan cada vez más hacia una economía de mercado.

PALABRAS CLAVE: Patrimonialismo. Formación del Estado. Capitalismo. Desarrollismo.

ABSTRACT: This paper presents an important debate that connects reflections of sociology with that of economic theory based on the same theme: the role of the State in Brazil and the importance of Portugal's heritage. We will sociologically analyze the connection between the patrimonialist political construction and the emergence of commercial capitalism, which results in a blockade of democracy and state modernization, and from an economic perspective, the approach of the same theme of the state as a driver of development throughout the XX

${ }^{1}$ Universidade Estadual do Sudoeste da Bahia (UESB), Vitória da Conquista - BA - Brasil. Departamento de Filosofia e Ciências Humanas. Doutor em História. ORCID: https://orcid.org/0000-0003-0302-2793. E-mail: silveira_lima@hotmail.com 
century, until the 1980s, when the strategies of growth and modernization from the developmental bias lose strength, becoming increasingly oriented towards a market economy.

KEYWORDS: Patrimonialism. Formation of the state. Capitalism. Developmentalism.

\section{Teses sobre o patrimonialismo no Brasil}

A definição de patrimonialismo, como um tipo ideal de configuração do Estado, aparece na obra de Max Weber como figura de transição entre as formas de dominação tradicional e burocrático-racional-legal (WEBER, 1999, p. 234). Para o autor, o critério de definição de suas características tem limites bastante claros na diferenciação entre público e privado, demarcando, de início, como o Estado foi se orientando cada vez mais para que o privado coubesse ao mercado, ao passo que ao Estado caberiam fenômenos de ordem pública, expressas nas condições de racionalização, sob a forma burocrática e de legalidade que passa a ser o seu padrão. O patrimonialismo é, então, um momento de transição em que o Estado estaria [ainda] sob domínio privado do Soberano e seus funcionários, mas cada vez mais perdendo essas características.

Na medida em que avançam as décadas após o período dos descobrimentos, Raymundo Faoro, principal estudioso do tema no Brasil, estabelece em Os donos do poder (1958) uma vinculação entre os fenômenos políticos de Portugal e sua colônia no continente americano:

Portugal não buscava, na América, o reflexo de suas instituições, numa réplica nova de um Reino velho - o que ele visava era o prolongamento passivo de suas instituições, armadas de poderes para criar, do alto, por obra da moldura jurídica, a vida política (FAORO, 2000, p. 167).

Assim, visando ao controle e à repressão, é fundada a cidade do Salvador. "A centralização era o meio adequado, já cristalizado tradicionalmente, para o domínio do Novo Mundo" (FAORO, 2000, p. 164), perspectiva que se aprofunda ferreamente no regime das Minas na virada para o século XVIII, com uma centralização tanto mais repressiva (FAORO, 2000, p. 171).

Prossegue afirmando que os episódios de 1808 geram demandas urgentes na Colônia, dentre as quais "organizar o Império, para o ministério, [o que] seria reproduzir a estrutura administrativa portuguesa no Brasil e colocar os desempregados" (FAORO, 2000, p. 284) ainda que criassem instituições que existiam em Portugal, mas sem atenção às especificidades do país que se estabelecia. 
Em resumo, haveria, para Faoro um continuum de centralização, que começa com os primórdios da constituição do capitalismo comercial sob hegemonia de um Estado empresarial (sec. XVI), dando a tônica do controle e repressão sobre as Minas recém-descobertas (no final do século XVII) e depois com o aporte gigantesco que a transferência da Corte em 1808 acarretará e que Faoro apresenta também como produto do caráter conciliador e policlassista do patrimonialismo português (FAORO, 200, p. 47), falando ainda em emancipação da classe miúda, nobilitada e ascendente social e politicamente depois da Revolução de 1385. (FAORO, 2000, p. 50). Na Colônia, tal processo dá-se de maneira idêntica: "Sociedade aristocrática, fixada no estamento em luta surda e tenaz contra a mercancia, que, incapaz, de se tornar independente, adere aos valores da nobreza, aos seus costumes e à sua ética" (FAORO, 2000, p. 200).

A perspectiva histórica com a qual Faoro atravessa os seis séculos, desde a Revolução de 1385 em Portugal chegando ao século XX, tem uma caracterização ideal-típica do patrimonialismo como conceito-chave. O modelo de Estado patrimonial que começa a se configurar a partir de 1385 em Portugal entra em confronto com características sociais organizadas de forma descentralizada, que é superada e sobre a qual o Estado português avança. Em seguida, esse patrimonialismo triunfante passa a ser o articulador de uma estrutura de poder que se realimenta indefinidamente, a partir da capacidade intrínseca de incorporar todas as demandas novas potencialmente conflitivas, mas desarticuladas em suas possibilidades transformadoras.

Assim, no esquema teórico de Faoro, o Estado é o elemento articulador de todo o mundo social português, tudo passa por ele e recebe a coação do seu peso e de sua dominação excessivas. Ainda que tal teorização, que é utilizada como instrumento analítico, como já dito, tanto da história portuguesa quanto do seu apêndice na América Portuguesa, entre em contradição com o eixo de argumentação de uma parcela expressiva da sociologia política brasileira, em especial de Oliveira Vianna (1987), Gilberto Freyre (2000) e Nestor Duarte (1966), que se aproximam de uma interpretação que considera a existência de feudalismo na história brasileira - feudalismo mais no sentido político - em que a Colônia seria um exemplo de sociedade de fragmentação política extremada, com ilhas econômicas que se articulam como vetores de poder local e, portanto, como empecilhos à constituição de um Estado centralizado, com uma autoridade e um eixo de poder bem definidos ${ }^{2}$.

${ }^{2}$ A idéia de feudalismo político converge com a relativamente recente tese do historiador português Antônio Manuel Hespanha, em Às vésperas do Leviathan (publicada em 1994) e que ele retoma de forma atualizada em As estruturas políticas em Portugal na época moderna (2001), onde são apresentados os fundamentos históricos 
Portanto, uma conciliação entre essas duas linhagens interpretativas, que retomam o patrimonialismo ou o feudalismo, não é possível nos termos propostos nos respectivos ensaios históricos de interpretação de cada um desses autores brasileiros. Só é possível encontrar uma mediação entre essas duas possibilidades, que dizem respeito ora a onipresença do Estado, ora a sua completa ausência, se considerarmos, retomando as teses de Simon Schwartzman (1975), no seu São Paulo e o Estado nacional, que a multiplicidade de realidades regionais trariam consigo formações diferentes, apontando tendencialmente para formas de dominação distintas sendo desenvolvidas de forma concomitante: predominantemente tradicionais e patriarcais no Nordeste e em Minas Gerais, ambos centros econômicos pujantes nos primeiros séculos da colonização e em decadência ao longo do século XIX. Por outro lado, o patrimonialismo teria fincado raízes mais profundas no Rio de Janeiro, antiga capital e centro da administração, que contrastaria de forma bastante acentuada com São Paulo, historicamente isolada, mas tendencialmente mais burguesa e, por isso, menos conectada com os ciclos de poder determinados pelas raízes patrimonialistas. A quarta região, o Rio Grande do Sul, geograficamente fronteiriço e por isso mais belicoso, desenvolve uma tendência militarista que se converte depois em positivismo e ocupa por força dessas características, e não de seu lado Europeu e moderno, um papel político hipertrofiado, em contraste com a diminuta presença política de São Paulo em face de sua pujança econômica adquirida ao longo de todo o século XIX.

Assim, haveria uma separação clara no Brasil já independente entre áreas mais patrimoniais - as duas primeiras - e outras mais capitalistas - as duas últimas - de modo que as condições socialmente conflitantes entre as diversas áreas geográficas do Brasil seriam equacionadas politicamente da seguinte forma: nas áreas mais tradicionais e patrimoniais, se atendendo às demandas de mobilidade social e, portanto, mais clientelísticas, ao passo que no segundo caso a política responderia aos grupos de interesses já claramente definidos economicamente. Chamando a atenção ainda para divisões entre setores rurais e urbanos e entre capitalistas e operários no interior de cada um desses sistemas, Simon Schwartzman conclui que é "elevado o número de possíveis combinações" (SCHWARTZMAN, 1975, p. 55), o que permite uma compreensão mais acertada da realidade do Estado brasileiro, sendo ela, portanto, muito mais complexa e multifacetada do que apresenta o esquema interpretativo mais rígido de Raymundo Faoro.

e sociológicos que amparam a sua hipótese de que Portugal tinha até o século XVIII uma estrutura descentralizada de tomada de decisões, de exercício do poder e de legitimações recíprocas entre as diversas esferas da sociedade portuguesa. 
Deste modo, a genealogia das tendências centralizadoras do Estado brasileiro, que trataremos adiante a partir da chave do conceito de nacional-desenvolvimentismo, que conduz a sociedade e a economia à modernização ao longo do século $\mathrm{XX}$, tem no patrimonialismo o seu histórico mais imediato. Foi desse modelo de relações estabelecidas entre o Rei, seus funcionários e a sociedade, que se forjou uma composição política estável, conduzindo o Estado ao primeiro plano das relações, inclusive econômicas, mas ressalvando, como propõe Schwartzman, que sua existência deve ser relativizada em contextos regionais e temporais específicos.

Se por um lado esse modelo patrimonialista atrofiou as pulsões econômicas nos primórdios do Brasil independente, a sua superação em países como França, Reino Unido e, depois, Estados Unidos, através de uma sociedade civil mais emancipada e com uma diversidade maior de classes sociais, conduziu a iniciativas importantes para a configuração de um mercado, mas também de relações de poder mais equilibradas entre as classes, atendendo, ainda, às demandas mercantilistas da classe burguesa que foi se tornando hegemônica. Em resumo, e seguindo as pistas de Faoro, a hipertrofia do Estado patrimonial foi, portanto, o entrave ao surgimento de uma burguesia forte na sociedade brasileira até meados do século XX. Por outro lado, a esse mesmo Estado também é atribuído o papel de indutor da superação da condição excessivamente periférica a que o país esteve relegado desde a sua independência (1822). Essa contradição fundamental só pode ser mais bem esclarecida se conhecida a trajetória percorrida pelo chamado Estado nacional-desenvolvimentista e a sua missão modernizadora ao longo do século XX.

É da contradição profunda de um Estado que cresce intermediando e amortecendo uma luta de classes que, de fato, nunca vem à tona pressionando a estrutura social do país, cuja estratificação eivada de desigualdade, dentre as maiores do mundo, sempre foi um sintoma inequívoco, e por outro lado esse mesmo Estado que se revela como fundamental para equacionar essas questões que passam, em distintos níveis, pelo atraso relativo da economia brasileira ao longo do século XX, cujo paulatino processo de transformação tem na atuação estatal um emulador imprescindível

\section{O Estado nacional e a indução do desenvolvimento}

Para posicionar essa contradição profunda sobre o papel do Estado no Brasil, a mudança de campo científico, da sociologia para a economia, esclarece melhor as leituras tão distintas sobre os significados desse Estado centralizado. 
O verdadeiro diálogo entre a análise econômica e análise sociológica, portanto, é do conhecimento, o da dependência do continente, dos limites da ação possível e da compreensão das políticas efetivamente implementadas, ao que vem somar-se a identificação dos autores ausentes e das dificuldades que se opõem à sua formação (TOURAINE, 2005, p. 20).

Assim, se esse tema é tratado por Raymundo Faoro (2000) como impedimento prolongado do desenvolvimento da indústria e do capitalismo moderno, para Simon Schwartzman (1975) o sistema é dualista: uma parte dele é tradicional enquanto a outra é mais burguesa e capitalista. Essa última parte é a referência que aparece nas reflexões de certa tradição da economia política no Brasil que compreende esse Estado centralizado como condutor do desenvolvimento pela via das induções promovidas nos setores estrangulados, os chamados gargalos do desenvolvimento. Esse modelo de relação com a economia ficará conhecido no Brasil como Estado nacional-desenvolvimentista e terá vida prolongada como realidade que orientou a maior parte do século XX.

A transição do modelo de ciclo econômico agroexportador para um complexo econômico que promovesse inversões de capital desses segmentos econômicos para outros setores da economia, tais como a indústria, estimulando o seu desenvolvimento, foi resultado, em grande medida, da formação do complexo econômico do café, constituído inicialmente na região do Vale do Paraíba, nos estados do Rio de Janeiro e São Paulo e, depois, ampliando-se para todo o Oeste Paulista.

Acredito ainda que a forma pela qual a intermediação financeira se apropriou de grande parte do capital cafeeiro, mascarou a sua origem, não se dando conta de que os capitais industrial, financeiro e comercial são eles próprios, fundamentalmente, faces do capital cafeeiro. Um ponto que reforça ainda mais o mascaramento da origem desses capitais do complexo paulista se deve à própria transferência de capital cafeeiro investido diretamente por fazendeiros ou via relações familiares - em atividades urbanas e que, em inúmeros casos, o transforma em banqueiro, industrial, comerciante, importador, etc., mesmo quando o fazendeiro não abandonou em definitivo sua condição anterior de capitalista rural (CANO, 1998, p. 98).

Entretanto, esse modelo agroindustrial e exportador e sua indústria rudimentar se mostra limitado frente à profunda recessão que tem início com os episódios da quebra da bolsa de Nova York em 1929. Daí por diante, precisamente, tem início as políticas de defesa do preço do café, interpretadas por Celso Furtado como política Keynesiana orientada à proteção de toda a renda nacional. Segundo o autor, "É, portanto, perfeitamente claro que a recuperação da economia brasileira, que se manifesta a partir de 1933, não se deve a nenhum fator externo, e sim à política 
de fomento seguida inconscientemente no país e que era um subproduto da defesa dos interesses cafeeiros" (FURTADO, 2005, p. 190).

Os momentos iniciais do primeiro governo, Getúlio Vargas atuará vigorosamente na defesa do preço do café, como defesa do conjunto da economia brasileira, mas também atuando em outra frente, que onerava as importações de produtos industriais tendo como perspectiva que a incipiente indústria nacional conseguisse competir no mercado interno, ampliando sua participação e diminuindo a dependência da economia brasileira em relação às oscilações dos preços internos do café e de outras commodities. Wilson Suzigan e Aníbal Villela, em um estudo sobre o tema, apresentam dados categóricos: enquanto em 1919 a produção industrial representava apenas $21 \%$ do PIB, em 1939 passa a ser a ordem de 43\%, (SUZIGAN; VILLELA, 1973, p. 238) $)^{3}$.

É revelador desse novo impulso toda uma mudança de posicionamento estratégico do Estado brasileiro frente a essa nova missão industrializante. "O Estado Novo tornou conhecidas e frequentes palavras como "plano", "planejamento", "planificação"”" (IGLESIAS, 2004, p. 79). Criaram-se serviços com esses nomes em todos os escalões administrativos e confirmava-se, assim, a superação da ideologia liberal pela intervencionista, protecionista, nacionalista. "A discussão sobre o desenvolvimento econômico e as políticas a serem seguidas era uma nova constante" (IGLESIAS, 2004, p. 79), muito embora não tivesse ainda uma conceituação que falasse em desenvolvimentismo, sendo o termo criado depois, mas aplicado retrospectivamente ao primeiro Governo Vargas, especialmente ao novo contexto inaugurado pelo Estado Novo a partir de 1937.

Na sequência ao modelo de desenvolvimento induzido por uma política de "substituição de importações", se agregaria um novo impulso, e a partir desse momento mais uma vez o estímulo da industrialização assim como foi durante toda da década de 1930 e metade da década de 1940: trata-se da nova situação de bipolaridade e uma feroz competitividade por espaços

\footnotetext{
${ }^{3}$ Em um estudo que se apresenta como atualização do debate proposto por Suzigan e Vilela (1973) CORONEL et al. (2014) contextualizam esse processo de fomento à indústria com os respectivos [e impressionantes] números. "No primeiro governo Vargas (1930-1945), observa-se a criação de vários órgãos, legislações e medidas que irão fomentar o crescimento do setor industrial, tais como criação do Ministério do Trabalho, Indústria e Comércio, Instituto do Açúcar e do Álcool, Código de Minas, Código de Águas, Instituto Brasileiro de Geografia e Estatística (IBGE), Comissão de Defesa da Economia Nacional, Consolidação das Leis Trabalhistas, expansão do crédito, criação da Carteira de Crédito Agrícola e Industrial do Banco do Brasil e da Superintendência da Moeda e do Crédito (Sumoc). Em 1934, o governo fez uma reforma tributária que atendia a vários anseios da classe empresarial. Também merecem destaque as ações de cunho macroeconômico como desvalorização real da taxa de câmbio, controle de câmbio e a captação e distribuição de poupança (IANNI, 1979). O resultado dessas medidas e ações refletiu-se no crescimento do setor industrial, sendo que a média anual, de 1933 a 1939, foi de 8,4\%, enquanto, na indústria de transformação, a média anual de crescimento no período foi de 11,3\%" (CORONEL, 2014, p. 109).
} 
geopolíticos que se estabelece entre os Estados Unidos e a então União das Repúblicas Socialistas Soviéticas (URSS). Neste contexto, cabe destacar a incorporação pelo Estado brasileiro das tecnologias que permitiram criar uma indústria nacional de siderurgia, com capital e tecnologia norte-americanas no período do imediato pós-guerra em 1945, fruto do alinhamento de Vargas ao esforço de guerra comandado pelos Estados Unidos. Esse seria um ponto de partida importante para que na década de 1950 se desenvolvesse a indústria de automóveis e de eletrodomésticos com capital europeu e, como resposta, também dos Estados Unidos na década seguinte. Finalmente, se delineia uma planificação estratégica a longo prazo que levou o Brasil a incorporar a seu parque industrial as tecnologias nucleares e a indústria petroquímica nas décadas seguintes, assim como da expansão significativa da infraestrutura de comunicações e transportes.

Ora, esse projeto de autonomia da economia brasileira foi implementada principalmente pelo Estado, durante quase seis décadas (1930-1980) e só se mostrou um modelo esgotado, e naquele momento por completo, devido à dívida externa resultante dessa política, especialmente a partir do Governo JK em 1955, que foi significativamente aumentada pela conjuntura das mudanças da política econômica dos Estados Unidos a partir de 1979, com um aumento dos juros e do dólar, que fizeram crescer de forma dramática os valores da dívida de países como o Brasil.

A crise, no entanto, apareceu como surpresa, pois "a economia brasileira no começo de 1979 dispunha de um montante de reservas que ensejava a percepção da existência de margem de manobra não desprezível para enfrentar os avatares da conjuntura internacional". (MACARINI, 2008, p. 7). O componente da surpresa estaria ligado ao aprofundamento da internacionalização, especialmente em sua dimensão financeira, mas não apenas nela (MACARINI, 2008, p. 51).

A sequência da crise econômica iniciada em 1979 é descrita, em seu desenvolvimento ao longo da década seguinte, em um artigo de Maria da Conceição Tavares (1985), afirmando à época que "Assim, enquanto nós [brasileiros] estamos obrigados a resolver o problema interno do financiamento público à custa da inflação e da elevação dramática dos juros internos, os EUA já não sofrem qualquer pressão nesse sentido" (TAVARES, 1985, p. 11, grifo do autor).

O prolongamento da crise enterra, portanto, o prosseguimento de políticas de desenvolvimento e coloca em primeiro plano a luta contra a inflação: ação que se tornou mais urgente para o Estado brasileiro e vai lhe ocupar todos os esforços em toda a década de 1980 perdurando até quase a metade da década seguinte. Assim, para Brasílio Sallum Jr., o último esforço industrializante do país fracassou porque atingiu os seus objetivos, com base numa 
tecnologia que estava em via de ser ultrapassada e apoiado em tal grau de endividamento que acabou por fragilizar sua própria mola impulsionadora, o Estado desenvolvimentista (SALLUM, 2000, p. 242-243).

Por essas razões, relacionadas com as limitações do Estado para seguir promovendo o desenvolvimento nacional, o país entra em um período de recessão cíclica e quase nulo crescimento econômico, para encontrar um novo projeto de gestão econômica, que tem lugar através das reformas do Estado e dos fundamentos econômicos no bojo da aplicação do Plano Real em 1994, executadas pelo governo do Presidente Itamar Franco e prosseguido no Governo seguinte de Fernando Henrique Cardoso, elegendo a luta contra a inflação como a mola mestra da reconstituição da economia do país, associada a uma redefinição - e que implicava diminuição - do papel do Estado, que irá retirar-se progressivamente das atividades econômicas do país ao longo de toda a década de 1990, sendo substituído, através de concessões e privatizações, pelo capital privado e pelas forças do mercado, que deveriam suprir a perda de capacidade de investimento por parte do Estado.

Desse modo, o Estado vai sendo retirado de setores importantes da economia, como as telecomunicações, os transportes, a mineração, o setor financeiro (basicamente através da venda de bancos estaduais), abrindo, em todos esses setores concessões para a iniciativa privada, na expectativa de que viessem a fazer vultuosos investimentos. Previsões que só se confirmam em alguns casos.

Politicamente, essa opção de retirada paulatina do Estado do fomento direto da economia e o desmonte do estado nacional-desenvolvimentista teve uma implicação bastante clara: na medida em que muitos setores da economia brasileira foram estimulados com aportes de capital privado, o Estado passou a ter uma arrecadação de impostos substantivamente maior, podendo fazer frente aos investimentos em políticas sociais e em infraestrutura, retomando nos últimos anos, ainda que timidamente, o caminho do desenvolvimento e constituindo um projeto de crescimento que se ensejava mais duradouro que a completa falta de projeto que foi a tônica da década de 1980.

Tal perspectiva que ocupou esse período compreendido entre 1994 e 2012 pelo menos revela essa retomada do desenvolvimento, ainda que repondo níveis do passado. Tendo como base o ano de 1994, de forte crescimento econômico no Brasil em relação aos anos anteriores $(5,9 \%)^{4}$, vemos que o período mais crítico de ajuste da economia brasileira - em que a indústria de bens de capital foi bastante sacrificada sofrendo retração econômica por quatro anos - dá 
lugar à reposição aos níveis mais altos da história recente da indústria de bens de capital no Brasil:

Segundo os indicadores da CEPAL podemos observar que: em 1994, a produção de bens de capital equivalia a um índice de 122 para cair a 97,9, em 1999, e subir a 125, em 2002 (CEPAL, 2005 apud MARTINS, 2007, p. 39).

Apesar de 2002, último ano do Governo de Fernando Henrique Cardoso e 2003, primeiro ano do Governo Lula ainda terem sido anos de baixo crescimento do PIB, respectivamente, $2,7 \%$ e 1,1\%, o período que vai de 2004 a 2007, já sob o Governo Lula, no entanto apresentou um significativo aumento do PIB, chegando a um crescimento médio anual de 4,5\% por quatro anos seguidos. O que parece um dado modesto pode ser interpretado à luz dos seguintes elementos: desde a década de 1970 o país não registrava crescimento acima de $3 \%$ por quatro anos seguidos; e essa série foi construída sem apelo a mecanismo inflacionários de crescimento.

Desse modo, a economia do Brasil mostrou fôlego e apresentava estar mais sólida com esse um novo ciclo de crescimento, mais modesto que nas décadas de 1960 e 1970, é bem verdade, mas com maior distribuição de renda ${ }^{5}$ e, principalmente, com democracia e com uma participação mais plural nos mecanismos de tomada de decisão, rompendo um padrão histórico de "crescimento do bolo para depois reparti-lo", como na famosa frase do ex-ministro Delfim Neto.

Nesse sentido, ainda que recente, uma avaliação do Governo Lula permite compreender que houve mais continuidades do que rupturas com o seu antecessor e ainda que este se auto intitulasse como Governo Neo-desenvolvimentista ${ }^{6}$, não é possível encontrar elementos socioeconômicos que permitam uma avaliação desse período como correlato ao que vimos chamamos de período nacional-desenvolvimentista (entre as décadas de 1930 e 1980) especialmente por que não incorporou tecnologia suficiente que permitissem superar gargalos tecnológicos, como aqueles que ainda nos separam da terceira Revolução Industrial,

${ }^{5}$ Com um índice de Gini em 1995 de 0,567, chegando a 0,570 em 1997, mas caindo em 2006 para 0,528. (Fonte: PNAD/IBGE. http://www.planalto.gov.br/2BalancoPAC.pdf, acesso em julho de 2016). Ainda nessa linha, segundo a Fundação Getúlio Vargas, "Em 1992, 32,52\% da população se enquadrava na classe média e esse contingente chegou a 47,06\% em 2007". Ver: http://www.agenciabrasil.gov.br/noticias/2008/09/19/materia.200809-19.7160397205/view, acesso em julho de 2016.

${ }^{6}$ Leitura que divulgada entre membros importante do Governo Lula, encontrou abrigo teórico mais substantivo na tese de doutorado de Aloisio Mercadante (2010), cujo eixo central de sua tese ele assim definiu: "Tais características distinguem historicamente o novo processo de desenvolvimento brasileiro não apenas do que se convencionou chamar de modelo neoliberal, mas também do antigo nacional-desenvolvimentismo. Assim, defendemos a tese de que se começou a gerar, no Brasil, o que denominamos aqui de "Novo Desenvolvimentismo", centrado, em sua primeira etapa, na distribuição de renda, inclusão social e combate à pobreza, e que vem moldando a história recente do país e o seu futuro" (MERCADANTE, 2010, p. 26). 
posicionando a economia brasileira num patamar imediatamente superior, como se verificou entre as décadas de 1940 e 1950.

É dessa perspectiva de revolucionar permanentemente as forças produtivas, o que foi constante desde o século XIX, que permitiu as condições de crescimento do capitalismo em seus primórdios. Tanto no Manifesto do Partido Comunista e depois de forma mais desenvolvida em $\mathbf{O}$ Capital $^{7}$, Karl Marx reitera o papel crucial da tecnologia para a reprodução do capital. Ora, é especificamente nesse elemento que a tese de Mercadante se contrai num vazio: a experiência brasileira mostra que os períodos de grandes avanços nas políticas sociais se deram em estrita consonância com avanços econômicos importantes, como na Era Vargas (1930-1945), enquanto o segundo momento de avanços estruturantes nas políticas sociais articuladas na Constituição de 1988 (propondo a universalização do ensino básico e fundamental; a criação do Sistema único de Saúde; bem como da aposentadoria pelo Funrural) levaram ainda quase uma década para tornar-se uma realidade tangível, exatamente porque foram propostas num contexto de estagnação econômica e sem lastro no orçamento do Estado.

O Governo Lula, que em muitos aspectos foi sim uma continuidade do seu predecessor, ainda carece de uma teorização mais realista que lhe posicione frente à história, o que é uma tarefa difícil, especialmente porque não consegue fugir completamente dessa interpretação lançada ainda em seus primórdios pelo sociólogo Francisco de Oliveira ${ }^{8}$. Sempre que se relacionam as duas experiências, de FHC e Lula, com o neoliberalismo, tal questão é sempre colocada de maneira descontextualizada: uma vez esgotado o modelo nacionaldesenvolvimentista ainda na década de 1980, qual saída seria possível para a retomada do crescimento econômico como lastro para um aprofundamento da distribuição de renda? O que os Governos de Fernando Henrique Cardoso (1995-2003) e Lula (2003-2011) mostraram empiricamente é que a estabilização econômica visando à contenção da inflação seria o fundamento do crescimento econômico, ainda que modesto, para a partir de então haver avanços nas políticas sociais. Essa tríade foi mantida a duras penas em ambos os casos. A experiência posterior do Governo de Dilma Rousseff (2011-2016) veio mostrando exatamente

7“'Com o crescimento da eficiência, do volume e do valor de seus meios de produção, portanto com a acumulação que acompanha o desenvolvimento de sua força produtiva, o trabalho mantém e perpetua, sob forma sempre nova, um valor-capital constantemente crescente" (MARX, 1996, p. 239).

8 "Nem o presidente nem muitos dos que estão nos ministérios nem outros que se elegeram para a Câmara dos Deputados e para o Senado da República pediram meu voto para conduzir uma política econômica desastrosa, uma reforma da Previdência anti-trabalhador e pró-sistema financeiro, uma reforma tributária mofina e oligarquizada, uma campanha de descrédito e desmoralização do funcionalismo público, uma inversão de valores republicanos em benefício do ideal liberal do êxito a qualquer preço - o "triunfo da razão cínica", no dizer de César Benjamin , uma política de alianças descaracterizadora, uma "caça às bruxas" anacrônica e ressuscitadora das piores práticas stalinistas, um conjunto de políticas que fingem ser sociais quando são apenas funcionalização da pobreza, enfim, para não me alongar mais, um governo que é o terceiro mandato de FHC" (OLIVEIRA, 2003). 
que foi a flexibilização das metas inflacionárias que contribuíram para um forte desequilíbrio orçamentário e, na sequência, à estagnação econômica seguida da maior retração econômica da história da República (entre os anos de 2014 e 2016), o que compromete a tese de Aloísio Mercadante de que o investimento social desacompanhado de uma severidade orçamentária e das metas de inflação seria capaz de gerar, por si só, crescimento econômico.

Ora, ainda assim, a autodefinição do Governo Lula, feita especialmente por um dos seus mais destacados estrategistas, Aloísio Mercadante, como sendo neo-desenvolvimentista permite avaliar que o termo se consagrou como referência positiva do papel e da presença do Estado como elemento ativo para superação da condição periférica.

O mesmo não pode ser dito do velho patrimonialismo, que segue sendo uma pecha negativa das mazelas de um Estado anti-moderno e explicação fundamental do histórico atraso brasileiro.

\section{Breve conclusão}

Assim, como vimos, o papel do Estado brasileiro, a depender do enfoque com que é analisado, apresenta-se de modo extremamente contraditório, oscilando da condição de instrumento de cooptação das classes sociais que lhe possam ser antagônicas, à condição de indutor do desenvolvimento e demiurgo da modernidade. A pedra angular da questão aparece nos significados que podem ser atribuídos ao "Estado Novo" que emerge com a Revolução de 1930 e se consolida a partir de 1937. Nesse momento, de centralização progressiva das instituições, se aumenta de maneira acentuada a regulação da vida política do país - até se atingir uma ditadura semifascista - mas também a regulação econômica - com um Estado interventor como já dito. A complexidade do quadro institucional e econômico do Brasil, nesse período, leva a interpretações bastante distintas sobre o real significado do Estado brasileiro no século XX. A severidade com que é tratada a tensão estabelecida entre a sociedade civil - impedida de se desenvolver plenamente - e o poder estatal - que se configura em termos autoritários - já foi motivo de interpretações bastante pessimistas sobre a possibilidade de constituição de um Estado democrático e moderno, caso do estudo de Raymundo Faoro (2000), publicado em 1958.

Apesar das distorções do autoritarismo e da perspectiva de cooptação de uma classe pela outra, e que foi a permanência mais viva do passado patrimonialista, é possível observar, com o devido distanciamento histórico, que tal fato esteve ligado ao modelo de Estado centralizado que foi ungido das forças culturais e políticas que permearam a missão de construção da nação e que, apesar dos óbices anunciados pelos críticos do modelo patrimonialista, foi nesse quadro 
de sobreposição do poder do Estado à sociedade, regulando e amortecendo os choques de classe, mas também direcionando esforços para a constituição de um modelo de relações sociais de produção (mundo do trabalho) e da incorporação de forças produtivas (tecnologia) que se conseguiu impulsionar o país a superar as condições limitadas de uma economia ainda predominantemente pré-capitalista, até meados da década de 1920, para um modelo que ingressava num capitalismo rudimentar, mas passível de ser aperfeiçoado, como veio a ser feito nas décadas seguintes.

Um caminho alternativo a esse, diz Jessé Souza, se configurou como solitária exceção, à medida que "Em sentido estrito, no entanto, foram apenas os Estados Unidos da América que lograram, construir uma sociedade na qual a presença de um forte Estado centralizado foi uma realidade tardia" (SOUZA, 2000, p. 172), todas as demais, em algum grau, estiveram expostas às formas de dominação tradicional que evoluem, depois, para um estado centralizado.

A trajetória deste Estado fortemente centralizado, ao mesmo tempo que inibiu a livre iniciativa econômica e, também, a livre associação da sociedade civil elevando-lhe o capital social e a cultura cívica ${ }^{9}$, conduziu, por outro lado, a formas mais concretas de desenvolvimento econômico, sobretudo se tivermos em conta o estabelecimento de uma indústria de bens-decapital que se constituiu desde a década de 1950 e em termos sociais, de uma legislação trabalhista que tem seu começo na década de 1930 e se aprimora paulatinamente nas décadas seguintes.

Portanto, o aperfeiçoamento deste modelo de industrialização é algo pretendido no momento atual no Brasil, assim como também é o legado mais vivo do passado patrimonialista, que é a chamada cooptação do trabalhador realizada, sob diversos aspectos, através da Consolidação das Leis do Trabalho (CLT) promulgada em 1943 e, ainda hoje, um fundamento essencial para a ampliação dos direitos sociais e mantida sob duríssimas lutas. São esses elementos que respondem substantivamente pelos avanços, ainda que modestos, da redução da desigualdade social no país. Portanto, se a presença do Estado foi muito grande durante o século XX, era absolutamente necessária e respondeu em grande medida aos importantes avanços que produziram a transformação de um país de modelo estritamente agroexportador até quase a metade do século XX, à condição de um país de economia complexa, com uma forte produção industrial ao final do mesmo. 


\section{REFERÊNCIAS}

CANO, Wilson. Raízes da concentração industrial em São Paulo. Unicamp, Campinas Instituto de Economia, 1998.

CORONEL, Daniel Arruda; AZEVEDO, André Filipe Zago de; CAMPOS, Antônio Carvalho. Política industrial e desenvolvimento econômico: a reatualização de um debate histórico. Revista Economia Política, São Paulo, v. 34, n. 1, p. 103-119, mar. 2014.

DUARTE, Nestor. A ordem privada e a organização política nacional. 2. ed. São Paulo: Companhia Editora Nacional, 1966.

FAORO, Raymundo. Existe um pensamento político brasileiro? São Paulo: Ática, 1994.

FAORO, Raymundo. Os Donos do Poder. São Paulo: Publifolha/Globo, 2000.

FREYRE, Gilberto. Casa-grande \& Senzala: formação da família brasileira sob regime de economia patriarcal. São Paulo/Rio de Janeiro: Record, 2000.

FURTADO, Celso. Formação econômica do Brasil. Companhia Editora nacional: São Paulo, 2005.

HESPANHA, Antonio Manuel. Às vésperas de Leviathan: Instituições e poder político, Portugal, Sec. XVII. Coimbrãs: Almedina, 1994.

HESPANHA, Antonio Manuel. As estruturas políticas em Portugal na época moderna. In: TENGARRINHA, José (Org.) História de Portugal, São Paulo: Editora UNESP/EDUSC, 2001.

IBGE - Instituto Brasileiro de Geografia e Estatística. Disponível em:

http://www.ibge.gov.br/home/presidencia/noticias/noticia_visualiza.php?id_noticia=321\&id_ pagina $=1$. Acesso em: 23 set. 2008.

IGLESIAS, Francisco. Aspectos políticos e econômicos do Estado novo. In:

SZMRECSÁNYI, T.; CORONEL, GRANZIERA. R. G. et al. Getúlio Vargas e a economia contemporânea. São Paulo, Campinas: HUCITEC, UNICAMP, 2004. p. 65-81.

MACARINI, José Pedro. Crise e política econômica: o Governo Figueiredo (1979-1984).

Texto para discussão. Campinas: IE/UNICAMP, n. 144, jun. 2008.

MARTINS, Carlos Eduardo. O Brasil e a dimensão econômico-social do governo Lula: resultados e perspectivas. Rev. Katálysis, Florianópolis, v. 10, n. 1, 2007. Disponível em: http://www.scielo.br/scielo.php?script=sci_arttext\&pid=S141449802007000100005\&lng=pt $\& n r m=$ iso. Acesso em: 23 set. 2008.

MARX, Karl. O Capital: Crítica da economia política. São Paulo: Nova Cultural, 1996.

OLIVA, Aloízio Mercadante. As bases do novo desenvolvimentismo = análise do governo Lula. 2010. 509 p. Tese (doutorado) - Universidade Estadual de Campinas, Instituto de 
Economia, Campinas, SP. Disponível em:

http://www.repositorio.unicamp.br/handle/REPOSIP/286345. Acesso em: 17 ago. 2018.

OLIVEIRA, Francisco de. Sociólogo Chico de Oliveira sai do PT. Folha de S. Paulo,

14.12.2003. Disponível em: http://www1.folha.uol.com.br/folha/brasil/ult96u56441.shtml. Acesso em: 23 set. 2008.

PUTNAM, Robert. Comunidade e democracia: a experiencia da Itália moderna. São Paulo: Editora FGVS, 1986.

SCHWARTZMAN, Simon. São Paulo e o Estado Nacional. São Paulo: DIFEL, 1975.

SOUZA, Jessé. A modernização seletiva, uma reinterpretação do dilema brasileiro. Brasília: UNB, 2000.

SUZIGAN, Wilson; VILLELA, Aníbal. Política do governo e crescimento da economia brasileira. Rio de Janeiro: IPEA, 1973.

TAVARES, Maria da Conceição. A retomada da hegemonia americana. Revista de Economia Política, v. 5, n. 2, abr.jun., 1985.

TOURAINE, Alain. O Brasil em desenvolvimento. In: CASTRO, Ana Célia et al. Brasil em Desenvolvimento: instituições, política e sociedade. Rio de Janeiro: Editora Civilização Brasileira, p. 17-38, 2005.

WEBER, Max. Economia e Sociedade. Brasília: Editora Universidade de Brasília, 1999.

\section{Como referenciar este artigo}

LIMA, Matheus Silveira. Formação do Estado brasileiro: entre o patrimonialismo e o desenvolvimentismo. Rev. Sem Aspas, Araraquara, v.8, n. 1, p. 15-29, jan./jun. 2019. e-ISSN: 2358-4238. DOI: $10.29373 /$ sas.v8i1.12768

Submetido em: 21/03/2019

Aprovado em: 04/05/2019 